\title{
Randomised, controlled trial of alternating pressure mattresses compared with alternating pressure overlays for the prevention of pressure ulcers: PRESSURE (pressure relieving support surfaces) trial
}

Jane Nixon, Gillian Cranny, Cynthia Iglesias, E Andrea Nelson, Kim Hawkins, Angela Phillips, David Torgerson, Su Mason, Nicky Cullum, on behalf of the PRESSURE Trial Group

\begin{abstract}
Objective To compare whether differences exist between alternating pressure overlays and alternating pressure mattresses in the development of new pressure ulcers, healing of existing pressure ulcers, and patient acceptability.

Design Pragmatic, open, multicentre, randomised controlled trial.

Setting 11 hospitals in six NHS trusts.

Participants 1972 people admitted to hospital as acute or elective patients.

Interventions Participants were randomised to an alternating pressure mattress $(\mathrm{n}=982)$ or an alternating pressure overlay $(\mathrm{n}=990)$.

Main outcome measures The proportion of participants developing a new pressure ulcer of grade 2 or worse; time to development of new pressure ulcers; proportions of participants developing a new ulcer within 30 days; healing of existing pressure ulcers; and patient acceptability.

Results Intention to treat analysis found no difference in the proportions of participants developing a new pressure ulcer of grade 2 or worse ( $10.7 \%$ overlay patients, $10.3 \%$ mattress patients; difference $0.4 \%, 95 \%$ confidence interval $-2.3 \%$ to $3.1 \%, \mathrm{P}=0.75)$. More overlay patients requested change owing to dissatisfaction $(23.3 \%)$ than mattress patients $(18.9 \%$, $\mathrm{P}=0.02$ ).

Conclusion No difference was found between alternating pressure mattresses and alternating pressure overlays in the proportion of people who develop a pressure ulcer.

Trial registration ISRCTN 78646179
\end{abstract}

\section{Introduction}

Pressure ulcers are areas of localised damage to the skin and underlying tissue caused by pressure, shear, friction, or a combination of these. ${ }^{1}$ Pressure ulcers range in severity (box 1). They are common in hospital, community, and nursing home populations (prevalence from $4 \%$ to $33 \%$ ). ${ }^{2}$

Strategies to relieve pressure include manual repositioning of patients or support surfaces such as cushions, mattress overlays, replacement mattresses or pressure relieving beds. A recent systematic review of 41 randomised controlled trials on pressure relieving surfaces for prevention of pressure ulcers concluded that the relative effectiveness of alternating pressure sur- faces is unknown. ${ }^{4}$ Alternating pressure surfaces consist of air filled sacs that sequentially inflate and deflate to relieve pressure for short periods. They are provided as either a full size replacement mattress or a shallower overlay that is placed on top of a mattress and are commonly used for people at moderate to high risk of pressure ulceration. An important clinical and economic question is whether alternating pressure replacement mattresses (about £4000; \$7464; €5847) confer any advantages over alternating pressure overlays (about £1000). We compared whether differences exist between alternating pressure overlays and alternating pressure mattresses in the development of new pressure ulcers, healing of existing pressure ulcers, and patient acceptability.

\section{Methods}

The pressure relieving support surfaces (PRESSURE) trial is a multicentre, randomised, controlled, parallel group trial in 11 hospitals in six NHS trusts. The target population was participants aged at least 55 years who had been admitted to vascular, orthopaedic, medical, or care of elderly people wards, either as acute or elective admissions, in the previous 24 hours. Other eligibility criteria were expected length of stay of at least seven days and either limitation of activity and mobility (Braden scale activity and mobility scores of 1 or 2 ; box $2^{5}$ ) or an existing pressure ulcer of grade 2 (using the skin grading tool from Nixon et al, ${ }^{3}$ box 1). Elective surgical patients without limitation of activity and mobility or an existing pressure ulcer were eligible if the average length of hospital stay for their surgical procedure

Box 1 Skin classification scale from Nixon et $\mathrm{al}^{3}$ with permission of Blackwell

- Grade 0-no skin changes

- Grade 1a-redness to skin (blanching)

- Grade $1 \mathrm{~b}$-redness to skin (non-blanching)

- Grade 2-partial thickness wound involving epidermis or dermis only

- Grade 3-full thickness wound involving subcutaneous tissue

- Grade 4-full thickness wound through subcutaneous tissue to muscle or bone

- Grade 5-black eschar 
Table 1 Operational definitions of support surfaces allocated to participants

\begin{tabular}{lcc} 
Characteristic & $\begin{array}{c}\text { Alternating pressure } \\
\text { overlay }\end{array}$ & $\begin{array}{c}\text { Alternating pressure } \\
\text { mattress }\end{array}$ \\
\hline $\begin{array}{l}\text { Alternating cell height minimum } \\
\text { (cm) }\end{array}$ & 8.5 & 19.6 \\
$\begin{array}{l}\text { Alternating cell height maximum } \\
\text { (cm) }\end{array}$ & 12.25 & 29.4 \\
\hline Cell cycle time (minutes) & $7.5-30$ & $7.5-30$ \\
\hline Cell cycle & 1 in 2,1 in 3, or 1 in 4 & 1 in 2,1 in 3, or 1 in 4 \\
\hline
\end{tabular}

was at least seven days or they were expected to have Braden scale activity and mobility scores of 1 or $2^{5}$ for at least three days postoperatively. Participants were not eligible if they had a pressure ulcer on admission of grade 3 or worse, had a planned admission to an intensive care unit after surgery, were admitted to hospital more than four days before surgery, slept at night in a chair, or weighed more than $140 \mathrm{~kg}$ or less than $45 \mathrm{~kg}$ (as per mattress specifications).

\section{Procedures}

Randomisation was through an independent, secure, 24 hour randomisation automated telephone system, ensuring allocation concealment. We used minimisation so that groups were comparable. We minimised on centre, existing pressure ulcer (yes or no), specialty (vascular, orthopaedic, medical, or care of elderly people), and type of admission (acute or elective).

Participants were allocated to an alternating pressure overlay or an alternating pressure mattress (table 1) within 24 hours of hospital admission. Elective surgical patients received their device on the day before surgery or after surgery at the point of transfer to bed.

The primary end point was the development of a new pressure ulcer of grade 2 or worse (box 1) on any skin site after baseline skin assessment and before trial completion. Clinical research nurses assessed skin status twice weekly for 30 days and then once a week up to 60 days. Grade 2 ulcers were chosen because they represent a break in the skin that is clinically meaningful and there is greater reliability in reporting these than for grade 1 ulcers. ${ }^{3}$ Patient acceptability was assessed indirectly from the number of people requesting a change because they were dissatisfied with the assigned surface. Healing end points included time to healing and grade of ulcer at trial completion. Complete healing was defined as "complete re-epithelialisation"; participants were considered "healed" if all their ulcers healed during the trial period.

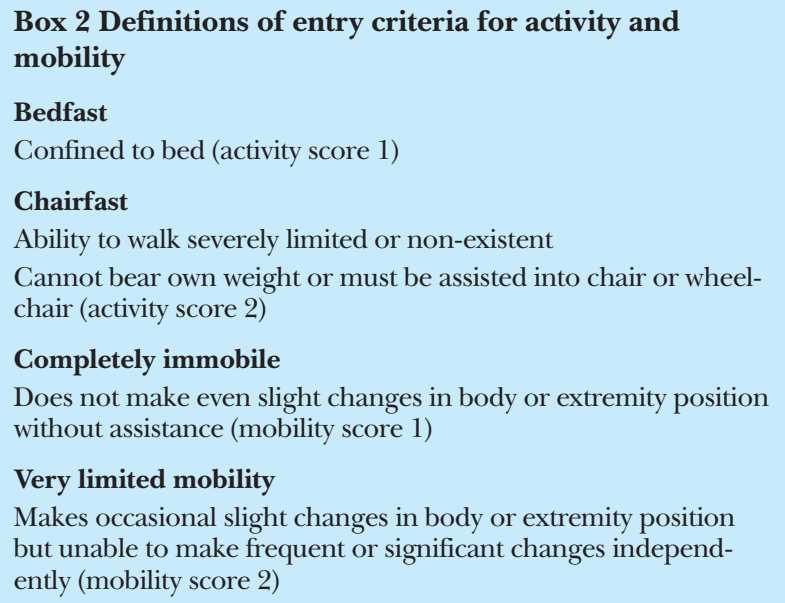

Trial completion was defined as participants fulfilling one of the following criteria: improved mobility and activity (Braden activity scores 3 or 4$),{ }^{5}$ a pressure ulcer of at least grade 2 that had resolved for three consecutive days as well as improved mobility and activity (Braden activity scores 3 or 4), transfer to a non-participating ward or consultant, discharge from hospital, 60 days from randomisation, or death.

We obtained informed written consent from the patients or assent from the relatives before participation. Relative assent was obtained for participants who were unable to give informed consent for reasons including unconsciousness, semiconsciousness, and confusion. Individual consent was sought when participants subsequently regained capacity.

\section{Statistical analysis}

We required a sample of 2000 participants for $80 \%$ power at the $5 \%$ significance level (two sided) to detect a $50 \%$ reduction in the proportion of people developing a pressure ulcer of grade 2 or worse. We aimed to recruit 2100 participants to allow for $5 \%$ loss to follow-up. The analysis was by intention to treat, with participants being analysed according to the group to which they were randomised.

The primary end point was compared between groups using a $\chi^{2}$ test. We also carried out logistic regression analysis to adjust for minimisation factors and prespecified baseline covariates of skin trauma on any site, wound on any site, non-blanching erythema (grade 1b) on any site, patient's age, Braden nutrition score, haemoglobin level, Braden activity score, and diabetes. We used a log rank test to compare the time to development of a new pressure ulcer and a $\chi^{2}$ test to compare the proportions of participants who developed a new pressure ulcer within 30 days of randomisation. As the data on area of new ulceration per patient were skewed we compared the maximum total area between the groups using a Mann-Whitney U test. We used a $\chi^{2}$ test to compare the proportions of participants between groups requesting a change owing to dissatisfaction with the trial surface. A log rank test was used to compare time to complete healing of existing ulcers between groups. We used a Cochran Armitage test for trend to compare the maximum grade of existing ulcers at trial completion between groups, on a per patient basis.

\section{Results}

Of 6155 people assessed for eligibility, 1972 were randomised from 10 of the 11 hospitals between January 2001 and April 2004 (figure). One patient was randomised twice and therefore excluded, providing an intention to treat population of 1971 people. The two groups were well balanced for baseline characteristics (table 2).

Overall, $207(10.5 \%)$ people developed a total of 305 new pressure ulcers, most of which $(n=297)$ were grade $2(97.4 \%)$. Eight people developed grade 3 ulcers: three in the overlay group and five in the mattress group. More of the acute patients developed a new pressure ulcer than the elective patients; medical or elderly patients were more likely to develop a new pressure ulcer than vascular or orthopaedic patients, and more people with an existing grade 2 ulcer than without at randomisation developed a new ulcer (table 3).

One hundred and six (10.7\%) people in the overlay group and $101(10.3 \%)$ people in the mattress group developed one or more new grade 2 pressure ulcers. The difference in the proportions of people with a new pressure ulcer (overlay - mattress) was $0.4 \%$ (95\% confidence interval $-2.3 \%$ to $3.1 \%)$. In the adjusted analysis the odds ratio for developing a new pressure ulcer using 
the overlay compared with the mattress was 0.94 (95\% confidence interval 0.68 to 1.29) indicating no difference between the surfaces in the odds of developing a new pressure ulcer $(\mathrm{P}=0.70$, logistic regression; table 4$)$.

Factors that had a significant effect on the proportion of people developing a new pressure ulcer were admission for an acute condition, the presence of a wound, skin trauma or non-blanching erythema on any site at baseline, age, haemoglobin level, and diabetes (table 4).

No statistically significant differences between the groups were found for development of a pressure ulcer within 30 days ( $10.0 \%$ overlay $v 9.3 \%$ mattress, $\mathrm{P}=0.58, \chi^{2}$ test $)$ or median time to development of a new pressure ulcer for the mattress group (56 days 95\% confidence interval 48 days, upper limit not estimable); the median for the overlay group had not been reached ( $\mathrm{P}=0.76, \log$ rank test). The groups had similar total areas for ulcers, with most new ulcers being small (median area $1.1 \mathrm{~cm}^{2}$, range $\left.0.1-68.1 \mathrm{~cm}^{2}\right)$. No evidence was found of a difference in median ulcer area between the groups $\left(1.2 \mathrm{~cm}^{2}\right.$ overlay $v$ $1.1 \mathrm{~cm}^{2}$ mattress, $\mathrm{P}=0.98$, Mann-Whitney $\mathrm{U}$ test).

\section{Patient acceptability}

In total 416 people requested one or more changes for comfort and other device related reasons: 230 (23.3\%) people in the overlay group and $186(18.9 \%)$ in the mattress group. Significantly more people allocated overlays requested a change (difference in proportions $4.4 \%, 95 \%$ confidence interval $0.7 \%$ to $7.9 \% ; \mathrm{P}=0.02, \chi^{2}$ test $)$.

\section{Healing of existing pressure ulcers}

Overall, 113 people had pressure ulcers at randomisation and, of these, $39(35 \%)$ healed during the trial: $34 \%(n=20)$ in the overlay group and $35 \%(n=19)$ in the mattress group. No statistically significant differences were found between the groups for median time to healing (20 days in both groups, $\mathrm{P}=0.86, \log$ rank test) or the maximum final ulcer grade per patient $(\mathrm{P}=0.96$, Cochran-Armitage test for trend).

In total, $349(17.7 \%)$ participants were not placed on the assigned surface at baseline: of these a device was unavailable for $43 \%(\mathrm{n}=151)$ and an alternative surface was allocated for $19 \%$ $(\mathrm{n}=66)$. More participants $(\mathrm{n}=10)$ randomised to an overlay than to a mattress $(n=2)$ were not placed on the assigned surface because of a clinical decision. In addition, ward staff initiated the change in surface for $149(15.1 \%)$ people in the overlay group and $142(14.5 \%)$ people in the mattress group. Some evidence was found of ward nurse preference for the replacement surface, with people perceived to be at high risk but assigned to overlay provided with a replacement mattress at baseline or subse-

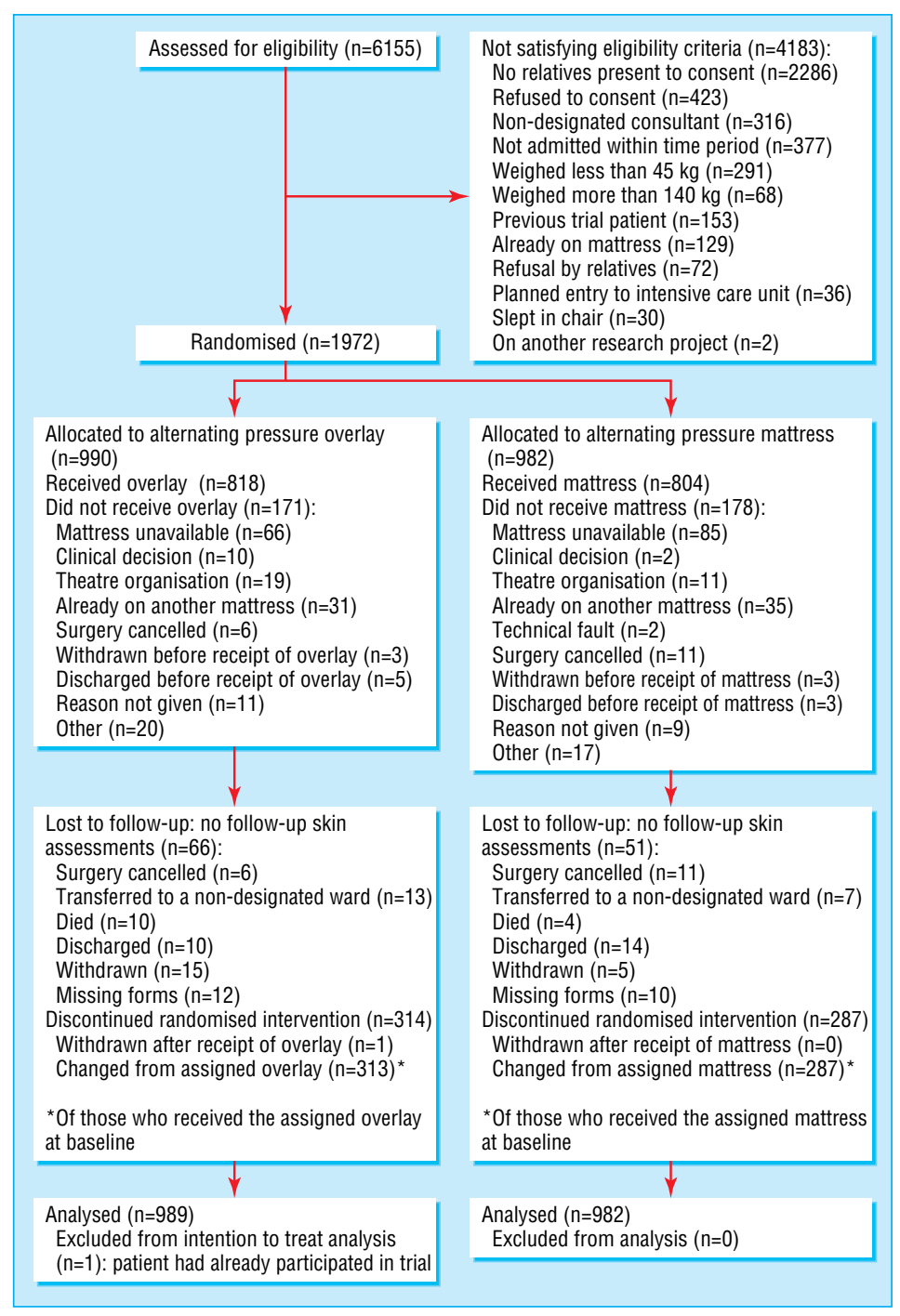

Flow of participants through trial 
Table 2 Baseline characteristics of participants allocated to alternating pressure overlay or alternating pressure mattress. Values are numbers (percentages) unless stated otherwise

\begin{tabular}{|c|c|c|c|}
\hline Characteristic & $\begin{array}{l}\text { Overlay group } \\
(\mathrm{n}=989)\end{array}$ & $\begin{array}{l}\text { Mattress group } \\
\quad(n=982)\end{array}$ & Total $(n=1971)$ \\
\hline Mean (SD) age (years) & $75.4(9.7)$ & $75.0(9.2)$ & $75.2(9.5)$ \\
\hline Median age (range) & $76.0(55.0-100.0)$ & $75.0(55.0-98.0)$ & $\begin{array}{c}76.0 \\
(55.0-100.0)\end{array}$ \\
\hline Men & $365(36.9)$ & $346(35.2)$ & $711(36.1)$ \\
\hline Women & $624(63.1)$ & $636(64.8)$ & $1260(63.9)$ \\
\hline \multicolumn{4}{|l|}{ Smoker: } \\
\hline Yes & 131 (13.2) & $123(12.5)$ & 254 (12.9) \\
\hline No & $852(86.1)$ & $855(87.1)$ & 1707 (86.6) \\
\hline Missing & $6(0.6)$ & $4(0.4)$ & $10(0.5)$ \\
\hline \multicolumn{4}{|l|}{ Diabetes: } \\
\hline Yes & $88(8.9)$ & $102(10.4)$ & $190(9.6)$ \\
\hline No & 895 (90.5) & 875 (89.1) & 1770 (89.8) \\
\hline Missing & $6(0.6)$ & $5(0.5)$ & $11(0.6)$ \\
\hline \multicolumn{4}{|l|}{ History of weight loss ${ }^{*}$ : } \\
\hline Yes & $75(7.6)$ & $95(9.7)$ & $170(8.6)$ \\
\hline No & $904(91.4)$ & 881 (89.7) & $1785(90.6)$ \\
\hline Missing & $10(1.0)$ & $6(0.6)$ & $16(0.8)$ \\
\hline \multicolumn{4}{|l|}{ Haemoglobin level $(\mathrm{g} / \mathrm{l}) \dagger:$} \\
\hline Mean (SD) & $129(18)$ & $130(17)$ & $129(18)$ \\
\hline Median (range) & $131(38-190)$ & $131(49-184)$ & $131(38-190)$ \\
\hline Missing & 53 & 50 & 103 \\
\hline \multicolumn{4}{|l|}{ Skin trauma: } \\
\hline Yes & $64 \quad(6.5)$ & 64 (6.5) & $128(6.5)$ \\
\hline No & $925(93.5)$ & 918 (93.5) & 1843 (93.5) \\
\hline \multicolumn{4}{|l|}{ Wound‡: } \\
\hline Yes & $57(5.8)$ & $60(6.1)$ & $117(5.9)$ \\
\hline No & $932(94.2)$ & 922 (93.9) & 1854 (94.1) \\
\hline \multicolumn{4}{|l|}{$\begin{array}{l}\text { Non-blanching erythema } \\
\text { (grade 1b): }\end{array}$} \\
\hline Yes & 180 (18.2) & 145 (14.8) & 325 (16.5) \\
\hline No & $809(81.8)$ & $837(85.2)$ & 1646 (83.5) \\
\hline \multicolumn{4}{|l|}{ Braden scale activity: } \\
\hline Bedfast & $804(81.3)$ & 754 (76.8) & $1558(79.0)$ \\
\hline Chairfast & $87(8.8)$ & $124(12.6)$ & $211(10.7)$ \\
\hline Walks occasionally & $20(2.0)$ & $31(3.2)$ & $51(2.6)$ \\
\hline Walks frequently & $52(5.3)$ & $49(5.0)$ & $101(5.1)$ \\
\hline Missing & $26(2.6)$ & $24(2.4)$ & $50(2.5)$ \\
\hline \multicolumn{4}{|l|}{ Braden scale nutrition: } \\
\hline Very poor & $403(40.7)$ & 371 (37.8) & 774 (39.3) \\
\hline Probably inadequate & $304(30.7)$ & $323(32.9)$ & $627(31.8)$ \\
\hline Adequate & $185(18.7)$ & $196(20.0)$ & 381 (19.3) \\
\hline Excellent & $71(7.2)$ & $67(6.8)$ & $138(7.0)$ \\
\hline Missing & $26(2.6)$ & $25(2.5)$ & $51(2.6)$ \\
\hline
\end{tabular}

*Weight loss $>6 \mathrm{~kg}$ in past six months.

†Measured on admission or preoperatively.

$\ddagger$ Wound on any site at baseline- - for example, leg ulcer, diabetic ulcer, surgical wound, and ischaemic or vascular ulcer.

quently changed to a replacement mattress. Furthermore, mattresses were more likely than overlays to be removed from a trial patient and allocated to a patient considered needier. The results of the cost effectiveness analysis are reported separately.

\section{Discussion}

The proportion of patients allocated to an alternating pressure overlay or alternating pressure mattress who developed a new pressure ulcer of grade 2 or worse at any anatomical site did not differ. These conclusions were confirmed by logistic regression to adjust for prespecified covariates and minimisation factors.

Most people develop pressure ulcers early in their hospital stay, but we found no statistically significant difference in the median time to new ulceration or in the proportion of people
Table 3 Development of new pressure ulcers by minimisation factors

\begin{tabular}{|c|c|c|c|}
\hline Factor & $\begin{array}{c}\text { No }(\%) \text { in } \\
\text { overlay group } \\
(\mathrm{n}=989)\end{array}$ & $\begin{array}{c}\text { No }(\%) \text { in } \\
\text { mattress group } \\
(n=982)\end{array}$ & Total $(n=1971)$ \\
\hline \multicolumn{4}{|l|}{ Type of admission: } \\
\hline Acute & $88 / 488$ (18.0) & $84 / 483$ (17.4) & 172/971 (17.7) \\
\hline Elective & $18 / 501$ (3.6) & 17/499 (3.4) & $35 / 1000$ (3.5) \\
\hline \multicolumn{4}{|l|}{ Type of specialty: } \\
\hline Vascular & $3 / 36(8.3)$ & 6/38 (15.8) & 9/74 (12.2) \\
\hline Orthopaedic & $75 / 785(9.6)$ & $66 / 779(8.5)$ & $141 / 1564(9.0)$ \\
\hline Elderly or medical & 28/168 (16.7) & 29/165 (17.6) & 57/333 (17.1) \\
\hline \multicolumn{4}{|c|}{ Existing grade 2 pressure ulcer: } \\
\hline Yes & $10 / 59(16.9)$ & 10/54 (18.5) & 20/113 (17.7) \\
\hline No & 96/930 (10.3) & 91/928 (9.8) & 187/1858 (10.1) \\
\hline
\end{tabular}

developing a new ulcer within 30 days. A cost effectiveness analysis undertaken alongside this trial, ${ }^{6}$ however, concluded that an alternating pressure mattress was cost effective as it was associated with a delay in ulceration (measured by Kaplan Meier estimates) and reduced costs as a consequence of shorter length of hospital stay.

The patient acceptability results indicate greater dissatisfaction with the overlay. Significantly more people using overlays $(23.3 \% v 18.9 \%)$ requested a change.

The analysis of risk factors confirmed the association of nonblanching erythema ${ }^{78}$ and increasing age ${ }^{910}$ with pressure ulceration whereas diabetes had only previously been identified as a factor in elderly nursing home residents ${ }^{11}{ }^{12}$ and anaemia in intensive care patients. ${ }^{13}$ The part that diabetes may play in the development of pressure ulcers is unclear; diabetic foot ulcers are usually a version of pressure damage and whether people with diabetes are more susceptible to pressure ulcers of the heel is something that deserves further scrutiny.

Our trial has several strengths; it was adequately powered to detect a clinically important effect on pressure ulcer risk even at fairly low rates of ulcer incidence, it was pragmatic and the findings are highly likely to be representative of what would happen in usual clinical practice, and it had broad specifications for eligible mattresses and overlays that ensured the results are likely to

Table 4 Adjusted analysis of proportion of patients developing a new pressure ulcer of grade 2 or worse

\begin{tabular}{|c|c|c|}
\hline Variable & Odds ratio $(95 \% \mathrm{CI})$ & $P$ value \\
\hline Support surface (overlay: mattress) & 0.94 (0.68 to 1.29 ) & 0.70 \\
\hline Hospital* $^{*}$ & & 0.02 \\
\hline Admission* (acute: elective) & 3.65 (2.27 to 5.85$)$ & $<0.0001$ \\
\hline \multicolumn{3}{|l|}{ Specialty*: } \\
\hline Vascular $v$ care of elderly people & 1.31 (0.51 to 3.33$)$ & 0.54 \\
\hline Orthopaedic $v$ care of elderly people & 1.28 (0.82 to 2.01$)$ & \\
\hline Existing pressure ulcer* (yes $v$ no) & 0.97 (0.52 to 1.79$)$ & 0.92 \\
\hline Baseline wound (yes $v$ no) & 2.96 (1.73 to 5.08$)$ & $<0.0001$ \\
\hline Baseline skin trauma (yes $v$ no) & 1.67 (0.999 to 2.80) & 0.05 \\
\hline Baseline ulcer grade $1 b$ (yes $v$ no) & 1.95 (1.31 to 2.91$)$ & 0.001 \\
\hline Age (years) & $1.02(1.002$ to 1.04$)$ & 0.03 \\
\hline Diabetes (yes $v$ no) & 1.61 (1.007 to 2.56) & 0.047 \\
\hline \multicolumn{3}{|l|}{ Braden activity: } \\
\hline Bedfast $v$ walks frequently & 0.70 (0.19 to 2.59$)$ & 0.22 \\
\hline Chairfast $v$ walks frequently & 0.36 (0.09 to 1.52$)$ & \\
\hline Walks occasionally $v$ walks frequently & 0.91 (0.16 to 5.08$)$ & \\
\hline $\begin{array}{l}\text { Braden nutrition (very poor or inadequate } v \\
\text { adequate or excellent) }\end{array}$ & 1.31 (0.81 to 2.13$)$ & 0.28 \\
\hline $\begin{array}{l}\text { Haemoglobin level on admission or } \\
\text { preoperatively }(\mathrm{g} / \mathrm{l})\end{array}$ & 8.9 (8.2 to 9.7$)$ & 0.1 \\
\hline
\end{tabular}

Small hospitals (<50 inpatient beds) were combined for analysis purposes to prevent problems from model convergence.

${ }^{*}$ Minimisation factors. 
be applicable to any surfaces that match these specifications. Finally, the rate of pressure ulceration $(10 \%)$ was well within the range of risk reported in previous trials in similar populations incorporating an alternating pressure arm. ${ }^{4}$

The main limitation of our trial was the lack of blinded outcome assessment; this is probably impossible to achieve in such trials because it is difficult to disguise or mask the mattresses and it would be unethical to frequently move seriously ill, elderly people on to a standard surface for their skin to be assessed. We took steps to minimise the potential for bias this allows by collecting independent skin assessments carried out by both the ward staff and the clinical research nurses.. ${ }^{3}$ Although ward nurses were not blind to allocation, we have no evidence that this influenced the care given. The frequent mattress changes were a strength of this trial as they represent the use of mattresses in real life and provide generalisable data.

We thank the following; the clinical research nurses: Helen Barrow, Caroline Cooper, Fiona Corcoran, Patricia Hutchinson, Yvonne Meades, Dawn Parkes, Fiona Smith, Ann Fotheringham, Sarah Gowland, Ann Warriner, Patricia Hutchinson, Caroline Smith, Richard Buckland, Monica Clark, Morag Doherty, Andrew Young, and Helen Marson; the participants and their relatives; ward nursing and medical staff of the six participating NHS trusts; and the independent trial steering committee for their guidance: Jenny Hewison (chair), David Machin, and Gerben ter Riet.

Contributors: NC, JN, AN, SM, and DT designed and initiated the trial. JN, $\mathrm{AP}$, and Helen Barrow coordinated the trial. GC and KH analysed the clinical data. CI and DT analysed the economic data. All authors met regularly and contributed to trial management; all participated in the interpretation of results and approved the paper. NC is the guarantor.

Funding: UK Department of Health through its health technology assessment programme. The opinions and conclusions expressed here are those of the authors and do not necessarily reflect those of the UK NHS or the Department of Health.

\section{What is already known on this topic}

No trials have directly compared alternating pressure replacement mattresses with less costly overlays in the prevention of pressure ulcers

\section{What this study adds}

No difference was found between alternating pressure replacement mattresses and alternating pressure overlays in proportion of people who develop pressure ulcers
Competing interests: JN has been reimbursed for attending conferences, has been paid speakers' fees, and received research funding from Huntleigh Healthcare.

Ethical approval: This study was approved by the north west multicentre research ethics committee and local ethics committees.

1 European Pressure Ulcer Advisory Panel. Pressure ulcer treatment guidelines. 1999. www.epuap.org/gltreatment.html (accessed 9 May 2006).

2 Kaltenhaler E, Whitfield MD, Walters SJ, Akehurst RL, Paisley S. UK, USA and Canada: how do their pressure ulcer prevalence and incidence data compare? J Wound Care 2001;10:530-5.

3 Nixon J, Thorpe H, Barrow H, Phillips A, Nelson EA, Mason S, et al. Reliability of pressure ulcer classification and diagnosis. J Adv Nurs 2005;50:613-23.

4 Cullum N, McInnes E, Bell-Syer SE, Legood R. Support surfaces for pressure ulcer prevention. Cochrane Database Syst Rev 2004;CD001735.

5 Bergstrom N, Braden BJ, Laguzza A, Holman V. The Braden scale for predicting pressure sore risk. Nurs Res 1987;36:205-10.

6 Iglesias C, Nixon J, Cranny G, Nelson EA, Hawkins K, Phillips A, et al. Cost effectiveness analysis. BMJ 2006;332:doi = 10.1136/bmj.38850.711435.7C.

7 Allman RM, Goode PS, Patrick MM, Burst N, Bartolucci AA. Pressure ulcer risk factors among hospitalized patients with activity limitation. JAMA 1995;273:865-70.

8 Reed RL, Hepburn K, Adelson R, Center B, McKnight P. Low serum albumin levels, confusion, and fecal incontinence:are these risk factors for pressure ulcers in mobilityimpaired hospitalized adults? Gerontology 2003;49:255-9.

9 Baum ho for pressure ulcers among elderly hip fracture patients. Wound Repair Regen for pressure ul $2003 ; 11: 96-103$.

10 Papanikolaou P, Clark M, Lyne PA. Improving the accuracy of pressure ulcer risk calculators: some preliminary evidence. Int J Nurs Stud 2002;39:187-94.

11 Brandeis GH, Ooi WL, Hossain M, Morris JN, Lipsitz LA. A longitudinal study of risk factors associated with the formation of pressure ulcers in nursing homes.J Am Geriatr Soc 1994;42:388-93.

12 Berlowitz DR, Brandeis GH, Morris JN, Ash AS, Anderson JJ, Kader B, et al. Deriving a risk-adjustment model for pressure ulcer development using the minimum data set. $J$ Am Geriatr Soc 2001;49:866-71.

13 Theaker C, Mannan M, Ives N, Soni N. Risk factors for pressure sores in the critically ill. Anaesthesia 2000;55:221-4.

(Accepted 24 March 2006)

doi $10.1136 /$ bmj.38849.478299.7C

Clinical Trials Research Unit, University of Leeds

Jane Nixon deputy director

Kim Hawkins assistant director (statistics)

Angela Phillips senior trial coordinator

$\mathrm{Su}$ Mason principal research fellow

Centre for Reviews and Dissemination, University of York

Gillian Cranny research fellow

Department of Health Sciences, University of York, York YO10 5DD

Cynthia Iglesias research fellow

David Torgerson professor

Nicky Cullum professor

School of Healthcare Studies, University of Leeds

E Andrea Nelson reader

Correspondence to: N Cullum nac2@york.ac.uk 